\title{
Reduced levels of growth hormone, insulin-like growth factor-I and binding protein- 3 in patients with shunted hydrocephalus
}

Tuija Löppönen, Anna-Liisa Saukkonen, Willy Serlo, Päivi Tapanainen, Aimo Ruokonen, Mikael Knip

\begin{abstract}
Objective-Children with hydrocephalus are characterised by slow linear growth in prepuberty, accelerated physical maturation during puberty, and reduced final height. We aimed to study the possible roles of growth hormone, insulin-like growth factor-I (IGF-I), and IGF binding protein-3 (IGFBP-3) in this growth pattern.
\end{abstract}

Study design-One hundred and fourteen patients with shunted hydrocephalus (62 males) aged 5 to 20 years, of whom 17 had spina bifida (six males), and 73 healthy controls (38 males) were studied. Anthropometric measures, body mass index, and body fat mass were assessed and the stage of puberty was determined. Serum growth hormone and plasma IGF-I and IGFBP-3 concentrations were measured.

Results-The patients comprised 44 (26 males) who were prepubertal and 70 (36 males) pubertal or postpubertal, while 32 of the controls (19 males) were prepubertal and 41 (19 males) pubertal or postpubertal. The prepubertal children with hydrocephalus had lower IGF-I $(p=0.002)$ and IGFBP-3 concentrations $(p<0.001)$ than the controls, and the pubertal children had four times lower basal growth hormone concentrations $(p<0.001)$. There was a correlation between height SD score and IGF-I levels in the total patientpopulation $(r=0.23 ; p=0.01)$. Peripheral IGF-I concentrations peaked at pubertal stages 2-3 in the female patients and at stage 4 in the controls. The prepubertal patients on antiepileptic treatment, carbamazepine in most cases ( $73 \%)$, had higher IGF-I ( $p=0.01)$ and IGFBP-3 concentrations $(p=0.03)$ than those who had never been treated with antiepileptic drugs, but still lower IGFBP-3 levels than the controls $(\mathrm{p}=\mathbf{0 . 0 1})$.

Conclusion- Based on these findings, it can be concluded that reduced growth hormone secretion may contribute to the pattern of slow linear growth and reduced final height observed in these patients. (Arch Dis Child 1997;77:32-37)

Keywords: hydrocephalus; growth hormone, insulinlike growth factor-I, insulin-like growth factor binding protein-3
Short stature and either advanced or delayed bone age have been reported previously in children with spina bifida and associated hydrocephalus. ${ }^{1-3}$ There are only a few reports on growth in children with hydrocephalus of an aetiology other than spina bifida, however. In the survey of Kaiser et al, $60 \%$ of the patients with shunted hydrocephalus without spina bifida (54/90) had abnormal endocrinological findings, including dwarfism, abnormal proportions, obesity, sexual precocity, or various combinations of these. ${ }^{4}$ Growth retardation (relative height below -2 SD scores) was present in $32 \%$ of the subjects (29/90). In our recent report on hydrocephalic children we observed that they experienced slow linear growth in prepuberty compared with controls and that their bone age was retarded, ${ }^{5}$ but that they had an earlier adolescent growth spurt and their bone age was advanced at that stage. The combination of retarded prepubertal growth and an early pubertal growth spurt resulted in reduced final height.

The short stature observed among these children has been attributed to various causes, for example shorter lower limbs and spinal deformities, including scoliosis. ${ }^{2}$ They may also have a risk of growth hormone deficiency as a consequence of various associated brain malformations. In a recent review, Rotenstein and Reigel report on 22 children with spina bifida, out of whom nine had maximal stimulated growth hormone values below $10 \mu \mathrm{g} / 1$, including two, who did not have hydrocephalus as well. ${ }^{6}$ There are also reports on growth hormone treatment of children with spina bifida, ${ }^{7}$ and a few other observations have been made of decreased growth hormone secretion ${ }^{8}$ and peripheral insulin-like growth factor-I (IGF-I) concentrations ${ }^{9}$ in hydrocephalic children with spina bifida.

Since previous studies on growth hormone release in children with hydrocephalus have focused mainly on patients with spina bifida, there is a lack of information on cases with some other aetiology. We provide here data on basal growth hormone, IGF-I, and IGF factor binding protein-3 (IGFBP-3) concentrations in 114 patients with shunted hydrocephalus (62 males) in relation to 73 healthy controls (38 males). The possible impacts of the slit ventricle syndrome (SLVS) and antiepileptic drugs on these parameters are also evaluated. Our working hypothesis was that disturbed growth hormone secretion may contribute to 
the pattern of slow linear growth and reduced final height observed in these patients.

\section{Subjects and methods}

The initial series consisted of 212 shunted hydrocephalic children aged 5 to 20 years who had undergone their primary operation at the Department of Paediatrics, Oulu University Hospital, Oulu, Finland, during a 26 year period from 1966 to 1991. Patients with tumours $(n=24)$ or achondroplasia $(n=3)$ were excluded, as also were patients with an intelligence quotient below $50 \quad(n=26)$, as factors other than the hydrocephalus itself may influence growth and pubertal development in such cases. Fourteen patients had moved to another university hospital district, and $30 \mathrm{had}$ died. One patient refused to participate. Thus the final population comprised 114 patients (62 males), including 17 with spina bifida (six males) and 97 without (56 males). The mean age in the total patient population was 11.8 years (range 5.0-19.9 years). Thirty eight children without spina bifida (23 males) were prepubertal, and 59 (33 males) were pubertal $(n=54)$ or postpubertal $(n=5)$. Six out of the 17 subjects with spina bifida were prepubertal and 11 pubertal or postpubertal.

The control subjects were recruited from among the appropriate age groups at neighbouring child welfare clinics and schools. They were invited to participate after thorough consultation with the child and their parents. One girl with diabetes and another 10.5 year old girl diagnosed in the course of this work as having coeliac disease were excluded, resulting in a final series of 73 controls ( 38 males), of whom 32 (19 males) were prepubertal and the remaining 41 (19 males) pubertal $(n=36)$ or postpubertal $(n=5)$. Their mean age was 12.0 years (range 5.1-19.7 years).

The clinical evaluation was carried out at the Department of Paediatrics, Oulu University Hospital. Informed consent was obtained from the subjects and/or their parents, and the research was conducted according to the Declaration of Helsinki. The median age of the hydrocephalic patients at the first operation had been 0.5 years (range $0.0-14.2$ years), the females having been operated on earlier than the males (median 0.2 (range 0.0-8.6) $v 0.7$ (range $0.0-14.2$ ) years; $\mathrm{p}=0.01$ ). The mean duration of the shunting period had been 10.0 (0.4) years. Most of the shunts were ventriculoperitoneal $(n=90)$, the remainder being ventriculoatrial $(n=24)$. An antisiphon device had been installed in 46 cases. The median number of shunt revisions was two per patient (range 0-14).

The aetiology was assessed according to a modification of the classification proposed by Amacher and Wellington, ${ }^{10-12}$ excluding neoplastic tumours as a possible aetiological condition (table 1). Magnetic resonance imaging was performed on a subgroup of 61 patients at the final evaluation and their aetiological diagnosis was based on these findings. ${ }^{13}$ The disease was congenital in almost $70 \%$ of the cases and acquired in one fourth, while
Table 1 The aetiology of hydrocephalus in the patients studied

\begin{tabular}{lc}
\hline & No (\%) \\
\hline Congenital & \\
$\quad$ Infantile obstructive hydrocephalus & $33(28.9)$ \\
Intracranial cerebrospinal fluid cysts & $20(17.5)$ \\
Other intracranial anomalies & $6(5.3)$ \\
Spina bifida & $17(14.9)$ \\
Acquired & \\
$\quad$ Perinatal (asphyxia and/or intracranial & \\
$\quad$ haemorrhage) & $25(21.9)$ \\
Infectious & $3(2.6)$ \\
Miscellaneous & $10(8.8)$ \\
Total & $114(100)$ \\
\hline
\end{tabular}

the remaining cases were of miscellaneous aetiology. ${ }^{5}$

Forty three patients were taking antiepileptic drugs at the time of the final evaluation, while 44 out of the 71 not doing so had never taken such drugs. Of the patients on anticonvulsive treatment, 33 were receiving monotherapy and 10 polytherapy. Carbamazepine was the most commonly used preparation, being taken as the only drug by 26 patients and in combination with at least one other antiepileptic drug by six patients.

All the patients and controls were examined by one of the authors (TL). Height was measured to the nearest $1.0 \mathrm{~mm}$ with a Harpenden wall mounted stadiometer and weight to the nearest $0.1 \mathrm{~kg}$ on electronic scales. Height SD score was assessed from Finnish growth charts. ${ }^{14}$ Body mass index (BMI) was calculated as the ratio between weight $(\mathrm{kg})$ and height squared $\left(\mathrm{m}^{2}\right)$. BMI SD score was assessed according to Finnish age and sex matched references. ${ }^{15}$ The triceps and subscapular skinfolds were measured to the nearest $0.1 \mathrm{~mm}$ with a Harpenden skinfold caliper, ${ }^{16}$ and body density was calculated from the combined result according to Parizkova. ${ }^{17}$ The percentage of body fat was calculated by the method described by Keys and Brozek. ${ }^{18}$ Waist and hip circumferences were measured to the nearest $1.0 \mathrm{~mm}$ with a metallic tape measure. ${ }^{19}$ All the anthropometric measurements were made three times and the mean value calculated for subsequent use. The stage of puberty was assessed according to Tanner and Whitehouse. ${ }^{20}$ Patients at stage 1 were classified as prepubertal and those at stage 5 as postpubertal.

SLVS associated with overdrainage of the cerebrospinal fluid may cause clinical symptoms such as low pressure headache, nausea, vomiting, disturbances in consciousness, haemiparesis, and epileptic seizures and increase the risk of further shunt complications. SLVS was considered to be present when apatient had paroxysmal activity in an electroencephalograph ${ }^{12}$ and clinical symptoms in addition to slit-like ventricles in computed tomography or magnetic resonance imaging.

LABORATORY METHODS

All blood samples were taken in the morning after an overnight fast. Serum growth hormone concentrations were measured radioimmunologically in duplicate using commercial reagents (Pharmacia Diagnostics, Uppsala, Swe- 
Table 2 Anthropometric measures of the prepubertal and pubertal patients with hydrocephalus and their controls. The values are means (95\% confidence interval)

\begin{tabular}{|c|c|c|c|c|c|c|}
\hline & \multicolumn{3}{|l|}{ Prepubertal } & \multicolumn{3}{|l|}{ Pubertal } \\
\hline & Patients $(n=44)$ & Controls $(n=32)$ & $p$ Value & Patients $(n=70)$ & Controls $(n=41)$ & $p$ Value \\
\hline Age (years) & 7.65 (7.04 to 8.25$)$ & 8.04 (7.33 to 8.75$)$ & 0.41 & $14.4(13.8$ to 15.1$)$ & $15.0(14.2$ to 15.8$)$ & 0.28 \\
\hline Height $(\mathrm{cm})$ & $122.0(118.0$ to 125.9$)$ & $129.6(125.3$ to 133.9$)$ & 0.01 & 159.1 (155.4 to 162.8$)$ & $165.9(162.0$ to 169.8$)$ & 0.02 \\
\hline Height (SD score) & $-0.78(-1.2$ to -0.35$)$ & $0.26(-0.07$ to 0.59$)$ & 0.001 & $-0.30(-0.79$ to 0.08$)$ & $0.46(0.12$ to 0.80$)$ & 0.01 \\
\hline Weight $(\mathrm{kg})$ & $25.5(22.8$ to 28.2$)$ & $27.3(25.1$ to 29.5$)$ & 0.10 & $56.1(52.3$ to 60.0$)$ & $53.9(50.2$ to 57.6$)$ & 0.41 \\
\hline $\mathrm{BMI}(\mathrm{kg} / \mathrm{m} 2)$ & $16.8(15.9$ to 1.7$)$ & $16.0(15.5$ to 16.6$)$ & 0.53 & $22.0(20.6$ to 22.9$)$ & $19.4(18.6$ to 20.2$)$ & 0.01 \\
\hline BMI (SD score) & $0.14(-0.32$ to 0.61$)$ & $-0.28(-0.58$ to 0.02$)$ & 0.30 & $1.05(0.59$ to 1.51$)$ & $-0.11(-0.42$ to 0.21$)$ & 0.001 \\
\hline Waist-hip ratio & $0.88(0.87$ to 0.90$)$ & $0.84(0.82$ to 0.85$)$ & 0.001 & $0.84(0.82$ to 0.85$)$ & $0.77(0.75$ to 0.78$)$ & 0.001 \\
\hline Body fat mass (\%) & $18.8(17.5$ to 20.2$)$ & $17.4(16.2$ to 18.7$)$ & 0.14 & $21.7(19.9$ to 23.6$)$ & $16.8(14.4$ to 19.2$)$ & 0.002 \\
\hline
\end{tabular}

den). Values below the limit of sensitivity, which was $0.3 \mu \mathrm{g} / \mathrm{l}$, were considered to be 0.3 $\mu \mathrm{g} / \mathrm{l}$. The intra-assay and interassay coefficients of variation were $7 \%$ and $12 \%$, respectively. Plasma IGF-I concentrations were analysed with a specific radioimmunoassay using commercial reagents (Incstar Corporation, Stillwater, Minnesota, USA) after extraction of the plasma samples with acid ethanol. The sensitivity was $1.0 \mathrm{nmol} / \mathrm{l}$ and the intra-assay and interassay coefficients of variation were $5 \%$ and less than $12 \%$, respectively. Serum IGFBP-3 concentrations were determined radioimmunologically (Diagnostic Systems Laboratories Inc, Texas, USA), a method which has a sensitivity of $30 \mu \mathrm{g} / \mathrm{l}$, an intra-assay coefficient of variation less than $5 \%$ and an interassay coefficient of variation less than $9 \%$.

\section{STATISTICS}

The results were analysed statistically by (a) cross tabulation and $\chi^{2}$ statistics when comparing qualitative data between the patients and the controls; (b) Student's $t$ test when comparing quantitative data between the two groups; and (c) Mann-Whitney $U$ test in cases of skewed distribution or ordinal variables. Covariance analysis was used to adjust for age where appropriate. Logarithmic transformation of continuous variables was performed to normalise their distribution if necessary. The

Table 3 Basal growth hormone concentrations ( $\mu \mathrm{g} / \mathrm{l}$ ) in 97 patients with hydrocephalus without spina bifida and 73 healthy controls. The values are mean (95\% confidence interval)

\begin{tabular}{lccccc}
\hline & Patients & No & Controls & No & p Value \\
\hline Age (years) & $7.8(7.1$ to 8.4$)$ & 38 & $8.0(7.3$ to 8.8$)$ & 32 & 0.54 \\
Prepubertal & $2.1(0.9$ to 3.2$)$ & 38 & $2.1(0.8$ to 3.5$)$ & 32 & 0.99 \\
Males & $2.0(0.3$ to 3.7$)$ & 23 & $2.9(0.7$ to 5.2$)$ & 19 & 0.37 \\
Females & $2.2(0.5$ to 3.9$)$ & 15 & $1.0(0.2$ to 1.8$)$ & 13 & 0.20 \\
Age (years) & $14.3(13.6$ to 15.0$)$ & 59 & $15.0(14.2$ to 15.8$)$ & 41 & 0.17 \\
Pubertal & $1.8(1.1$ to 2.5$)$ & 59 & $8.5(5.6$ to 11.3$)$ & 41 & 0.001 \\
Males & $0.5(0.3$ to 0.6$)$ & 33 & $10.3(5.2$ to 15.3$)$ & 19 & 0.001 \\
Females & $3.4(2.0$ to 4.7$)$ & 26 & $6.9(3.7$ to 10.1$)$ & 22 & 0.19 \\
\hline
\end{tabular}

Table 4 Basal growth hormone ( $\mu \mathrm{g} / \mathrm{l}), I G F-I$ (nmol/l), and IGFBP-3 (mg/l) concentrations in 17 spina bifida patients with hydrocephalus and 73 healthy controls. The values are mean (95\% confidence interval)

\begin{tabular}{lllr}
\hline & Patients & Controls & p Value \\
\hline Prepubertal & $(\mathrm{n}=6)$ & $(\mathrm{n}=32)$ & \\
Age (years) & $7.0(4.6$ to 9.3$)$ & $8.0(7.3$ to 8.8$)$ & 0.17 \\
Basal growth hormone & $1.0(-0.70$ to 2.8$)$ & $2.1(0.8$ to 3.5$)$ & 0.81 \\
IGF-I & $5.2(3.1$ to 7.4$)$ & $12.4(10.8$ to 13.9$)$ & 0.001 \\
IGFBP-3 & $1.9(1.2$ to 2.7$)$ & $3.7(3.4$ to 4.0$)$ & 0.001 \\
Pubertal & $(\mathrm{n}=11)$ & $(\mathrm{n}=41)$ & \\
Age (years) & $15.1(12.8$ to 17.4$)$ & $15.0(14.2$ to 15.8$)$ & 0.96 \\
Basal growth hormone & $2.7(-0.87$ to 6.2$)$ & $8.5(5.6$ to 11.3$)$ & 0.02 \\
IGF-I & $15.9(10.8$ to 21.0$)$ & $21.3(19.1$ to 23.6$)$ & 0.03 \\
IGFBP-3 & $4.1(2.6$ to 5.5$)$ & $4.3(4.0$ to 4.6$)$ & 0.33 \\
\hline
\end{tabular}

results are expressed as mean $(95 \%$ confidence interval) unless otherwise indicated.

\section{Results}

Both the prepubertal and pubertal patients were significantly shorter than their controls, while the waist-hip ratio was increased in both groups of patients. The pubertal patients also had increased BMI, BMI SD score, and body fat mass compared with the controls (table 2).

The basal growth hormone concentrations were significantly lower in the hydrocephalic patients without spina bifida than in the controls (1.90 (1.28 to 2.53) v 5.68 (3.87 to $7.50) \mu \mathrm{g} / \mathrm{l} ; \mathrm{p}=0.00)$, and they also tended to have lower IGF-I (15.5 (13.8 to 16.6) $v 17.4$ (15.6 to 19.2$) \mathrm{nmol} / \mathrm{l} ; \mathrm{p}=0.09)$, and significantly reduced IGFBP-3 (3.6 (3.3 to 3.8) $v 4.0$ (3.8 to 4.2$) \mathrm{mg} / \mathrm{l} ; \mathrm{p}=0.005)$.

There were no significant differences in basal growth hormone between the prepubertal patients without spina bifida and their controls (table 3), whereas the pubertal patients, the males in particular, had significantly reduced basal growth hormone concentrations. Both IGF-I (9.3 (8.0 to 10.6$) v 12.4$ (10.8 to 13.9$)$ $\mathrm{nmol} / \mathrm{l} ; \mathrm{p}=0.002)$ and IGFBP-3 concentrations $(2.6$ (2.2 to 2.9$)$ v 3.7 (3.4 to 4.0$) \mathrm{mg} / \mathrm{l}$; $\mathrm{p}<0.001)$ were lower in the prepubertal patients than in the controls, both these differences being significant in the boys but only that in peripheral IGFBP-3 concentrations in the girls (figs 1 and 2). There were no significant differences in IGF-I or IGFBP-3 levels between the pubertal patients and the controls, but peak plasma IGF-I was observed to occur at pubertal stages $2-3$ in the hydrocephalic females but at stage 4 in the controls (fig $2 \mathrm{~A}$ ). The 17 patients with spina bifida tended to have lower basal growth hormone concentrations (data not shown), and there was a significant difference on this parameter between the pubertal patients with spina bifida and the pubertal controls (table 4). Both the prepubertal and pubertal spina bifida patients had reduced peripheral IGF-I, while IGFBP-3 concentrations were lower in the prepubertal patients with spina bifida, but not in the pubertal ones.

Height SD score was correlated with peripheral IGF-I concentrations $(r=0.23 ; \mathrm{p}=0.01)$ in the total patient population, while its association with IGFBP-3 remained non-significant $(r=0.14 ; \mathrm{p}=0.13)$. The correlation with IGF-I levels was closer in the males $(r=0.37$; $\mathrm{p}=0.003)$ than in the females $(r=0.21 ; \mathrm{p}=$ $0.13)$, although it was significant among the 

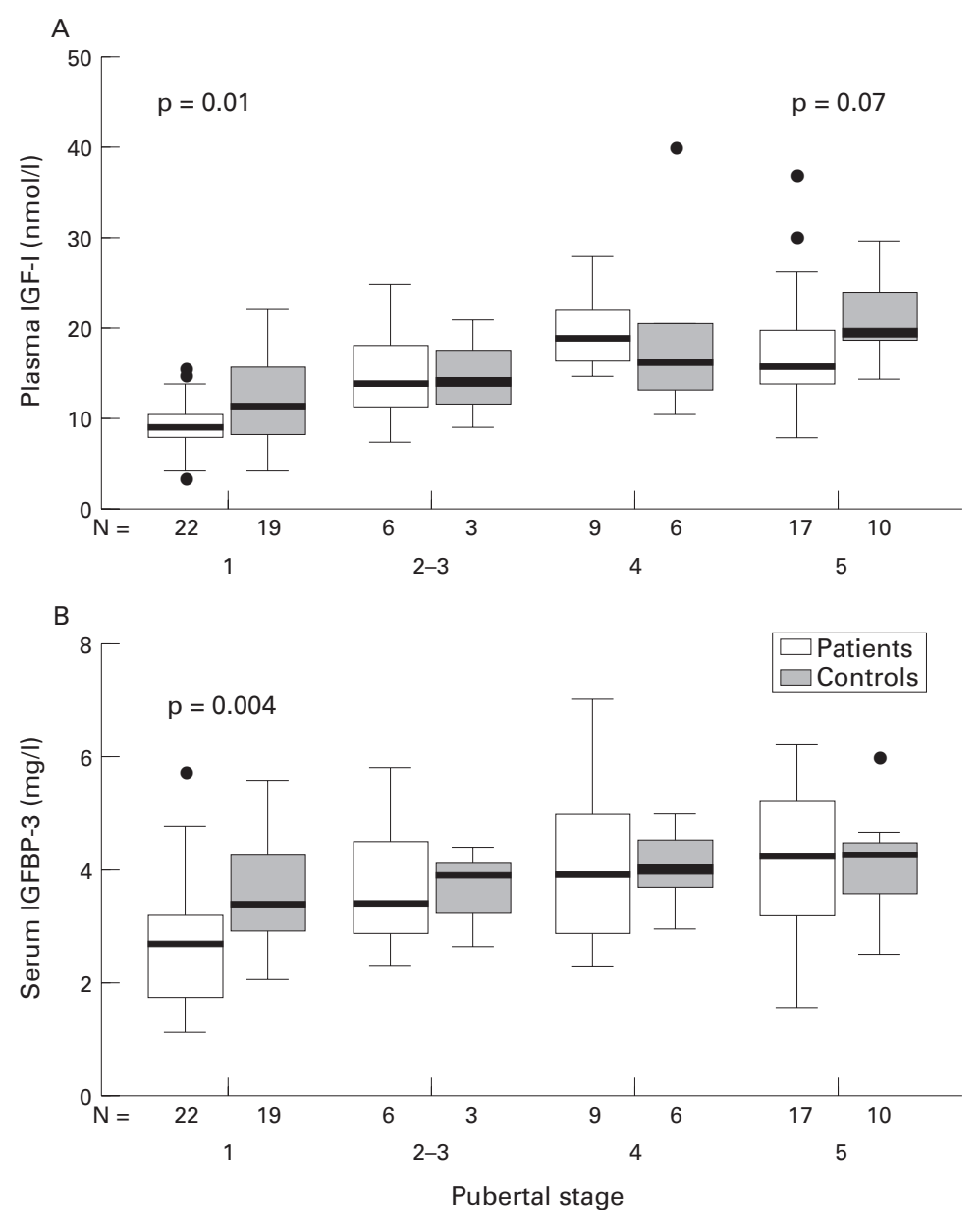

Figure 1 Plasma IGF-I $(A)$ and serum IGFBP-3 (B) concentrations in the male hydrocephalic patients without spina bifida and their controls by stage of puberty. Each box plot represents the median (thick black band) and the 25th and 75th centiles. The error bars represent the smallest and largest observed values that are not outliers $(\bullet)$. The prepubertal patients had significantly reduced IGF-I and IGFBP-3.

pubertal girls $(r=0.39 ; \mathrm{p}=0.02)$ but not among the boys $(r=0.17 ; \mathrm{p}=0.32)$. There was a positive correlation between IGFBP-3 levels and BMI ( $r=0.37 ; \mathrm{p}=0.009)$ and the proportion of body fat $(r=0.35 ; \mathrm{p}=0.01)$ among the prepubertal patients, and those correlations remained significant in a multiple regression analysis with age as the other dependent variable. There were no correlations between IGF-I or IGFBP-3 concentrations and anthropometric measures among the pubertal subjects.

Thirty five patients $(31 \%)$ fulfilled the criteria for SLVS. No significant differences in basal growth hormone or peripheral IGF-I concentrations were found between those with SLVS and those without, even when the two groups were split according to sex or pubertal stage (data not shown), but the males with SLVS $(n=22)$ had significantly higher IGFBP-3 concentrations than those without SLVS $(n=40)$ (4.2 (3.5 to 5.0) v 3.0 (2.7 to 3.4$) \mathrm{mg} / \mathrm{l}$; $\mathrm{p}=0.01)$. A higher proportion of the patients with SLVS $(21 / 35,60 \%)$ were being treated with antiepileptic drugs than of those without SLVS $(22 / 79,28 \%$; $=0.001)$.

The patients being treated with anticonvulsive drugs had basal growth hormone concen- trations of the same magnitude as those who had never received them (data not shown). Both circulating IGF-I (10.9 (8.6 to 13.2$) v 7.7$ (6.5 to 9.0 ) $\mathrm{nmol} / \mathrm{l} ; \mathrm{p}=0.01$ ) and IGFBP-3 concentrations (3.0 (2.2 to 3.8$) v 2.1$ (1.7 to 2.4) $\mathrm{mg} / \mathrm{l} ; \mathrm{p}=0.03$ ) were higher in the prepubertal patients on anticonvulsive drugs $(n=16)$ than in those never treated with them $(n=21)$, but no such differences were observed among the pubertal patients. Serum IGFBP- 3 concentrations (3.0 (2.2 to 3.8 ) v 3.7 (3.4 to 4.0 ) $\mathrm{mg} / \mathrm{l}$; $\mathrm{p}=0.01)$ were still lower in the prepubertal patients treated with anticonvulsive drugs than in the prepubertal controls, while there was no significant difference between these two groups in IGF-I concentrations (10.9 (8.6 to 13.2) $v$ $12.4(10.8$ to 13.9$) \mathrm{mg} / \mathrm{l} ; \mathrm{p}=0.28)$. The prepubertal patients who had never been treated with antiepileptics did not differ in relative height from those currently taking them $(-0.5(-1.2$ to 0.2$) v-1.3(-2.0$ to -0.5$)$ SD scores; $\mathrm{p}=0.16)$ nor was there any difference among the pubertal patients in this respect $(-0.2(-1.1$ to 0.8$) v-0.3(-1.0$ to 0.3$)$ SD scores; $\mathrm{p}=0.77)$.

\section{Discussion}

Growth hormone exerts many of its biological effects by stimulating the production of IGF-I in the liver and other target tissues. ${ }^{21}$ IGF-I is the main mediator of the growth promoting actions of growth hormone, and its circulating concentrations are regulated by growth hormone and reflect the endogenous secretion of the latter. ${ }^{22}$ Peripheral IGF-I concentrations in childhood increase with age and pubertal development, ${ }^{23}$ so that girls have their maximal IGF-I levels around the age of 14.5 years and boys about one year later, that is almost two years later than the average age for peak height velocity. By that time testosterone concentrations have increased in boys to approximately the levels seen in adult males. ${ }^{24}$ Peripheral IGF-I concentrations decrease after puberty, and this trend continues throughout adulthood. In addition to growth hormone, peripheral concentrations of IGF-I are affected by nutritional status and hepatic function. ${ }^{22}$ The large molecular weight binding protein IGFBP-3 (150 kilodaltons) binds approximately $90 \%$ of the circulating IGF-I. ${ }^{25}$ Peripheral IGFBP-3 concentrations, which appear to reflect integrated growth hormone secretion over several days and are low in patients with growth hormone deficiency, ${ }^{26}$ may offer a potential screening tool for growth hormone deficiency, as there seems to be less overlap between growth hormone deficient children and those with normal growth hormone secretion in the case of IGFBP-3 than for IGF-I concentrations. ${ }^{27-29}$

The present results suggest that both prepubertal and pubertal children with shunted hydrocephalus have indications of reduced growth hormone secretion. The prepubertal children with hydrocephalus had basal growth hormone concentrations similar to those seen in the control subjects but decreased IGF-I and IGFBP-3, while the pubertal children with hydrocephalus had clearly reduced basal 

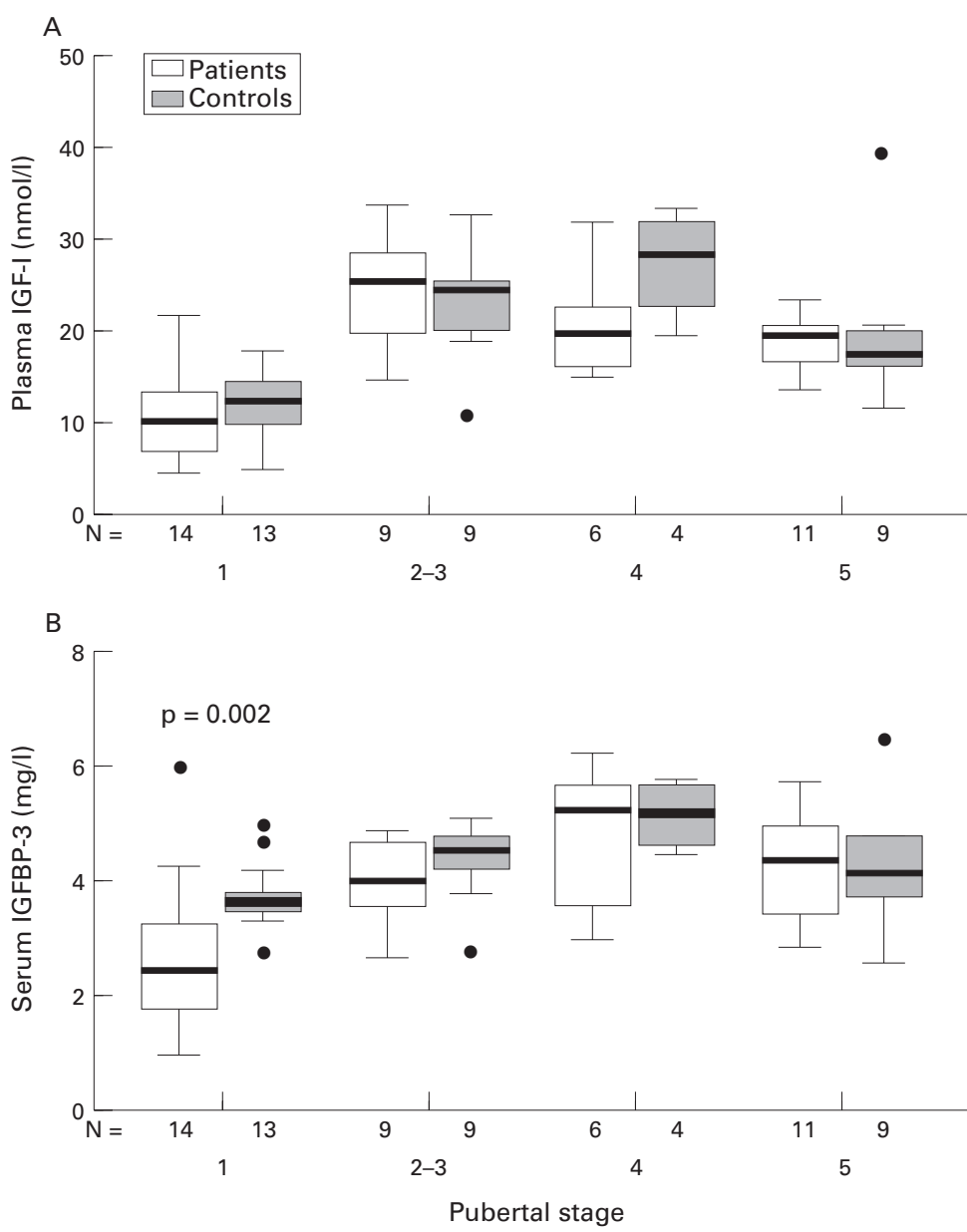

Figure 2 Plasma IGF-I $(A)$ and serum IGFBP-3 (B) concentrations in the female hydrocephalic patients without spina bifida and their controls by stage of puberty. Each box plot represents the median (thick black band) and the 25th and 75th centiles. The error bars represent the smallest and largest observed values that are not outliers $(\bullet)$. The prepubertal patients had significantly lower IGFBP-3.

growth hormone. A single basal growth hormone concentration provides very limited information on individual growth hormone secretory capacity, and it was unfortunately not possible for us to perform pituitary stimulation tests on all 114 patients. We have studied almost a half of the patients more closely, however, and have observed that about one third had a reduced peak growth hormone response $(<10 \mu \mathrm{g} / \mathrm{l})$ in an arginine-insulin test, ${ }^{30}$ confirming insufficient growth hormone secretion in a substantial proportion of these patients. Basal concentrations may reflect differences in growth hormone secretion between groups of individuals, especially in puberty, when daytime growth hormone pulses become more frequent, ${ }^{28}$ and from that point of view it is not surprising that we could not detect any significant differences in basal growth hormone concentrations between the patients with hydrocephalus and the controls in prepuberty, although the patients definitely had reduced IGF-I and IGFBP-3. On the other hand, the hydrocephalic patients had conspicuously reduced basal growth hormone in puberty in spite of there being no significant differences in peripheral IGF-I and IGFBP-3 concentrations between the groups. IGF-I concentrations vary markedly with pubertal stage, ${ }^{31}$ and reach a peak at an earlier stage in patients with hydrocephalus, especially in females. This pattern may reflect accelerated pubertal development in patients with hydrocephalus, ${ }^{32}$ obviously induced by enhanced gonadotrophin secretion, resulting in activation of the gonads. The increased release of sex steroids may then lead to growth hormone independent stimulation of hepatic IGF-I and IGFBP-3 synthesis. ${ }^{33}$

It has been demonstrated that growth hormone synthesis and secretion are reduced in the presence of obesity, ${ }^{34-36}$ whereas the influence of the latter on peripheral IGF-I levels is controversial, with reports of increased, ${ }^{37}$ normal, ${ }^{38}$ or even low levels ${ }^{39}$ compared with age matched controls. Even so, Juul et al did not find any correlation between serum IGF-I concentrations and BMI in a large survey of 877 healthy prepubertal children. ${ }^{23}$ Likewise, no correlation was seen between circulating IGF-I concentrations and BMI, triceps skinfold thickness, waist-hip ratio, height, or weight in 11-15 year old girls. ${ }^{40}$ The present prepubertal patients were not overweight and yet they still had reduced IGF-I and IGFBP-3 concentrations. The pubertal patients were obese compared with the controls, and this may partly explain their lower growth hormone levels.

Our findings fit well into the growth pattern described for hydrocephalic children in our previous report, ${ }^{5}$ with retarded linear growth in prepuberty but an earlier adolescent growth spurt, resulting in decreased final height. The reduced growth hormone secretion in prepuberty is likely to contribute to the slow growth at that stage, while that in puberty may result in a suboptimal adolescent growth spurt, at the same time as accelerated physical maturation leads to early fusion of the epiphyses.

Anticonvulsive drugs may have adverse endocrine effects in adults. ${ }^{41} 42$ It has recently been shown that women treated with carbamazepine have increased circulating concentrations of IGF-I and IGFBP-3, probably as a consequence of the direct hepatocellular effect of the drug. ${ }^{43}$ So far, no information has been available on the possible effects of anticonvulsive drugs on peripheral IGF-I or IGFBP-3 concentrations in children and adolescents, but the present observations indicate that carbamazepine may induce an increase in circulating IGF-I and IGFBP-3 levels, as the prepubertal patients on antiepileptics had higher concentrations than those who had never been treated with these drugs and more than $70 \%$ of the children receiving anticonvulsive treatment were taking carbamazepine. In addition, the male patients with SLVS had higher IGFBP-3 concentrations than those without SLVS, which may reflect the higher frequency of anticonvulsive treatment among children with this syndrome.

The results show that both prepubertal and pubertal children with hydrocephalus have signs of reduced growth hormone secretion, and that this is probably partly responsible for the growth pattern characteristic of such patients, including slow prepubertal growth, a 


\section{Key messages}

- Prepubertal children with shunted hydrocephalus have reduced circulating IGF-I and IGFBP-3 concentrations

- Pubertal children with shunted hydrocephalus have reduced basal serum growth hormone concentrations

- Reduced growth hormone secretion may contribute to slow linear growth and reduced final height in hydrocephalic children

- Carbamazepine treatment may increase IGF-I and IGFBP-3 concentrations in the peripheral circulation

suboptimal pubertal growth spurt and deficient final height. One can speculate that these findings may be a consequence of unphysiological increases or decreases in intracranial pressure.

We thank Sirpa Anttila and Riitta Päkkilä for their skilful techical assistance.

This work was supported by the Sigrid Jusélius Foundation, Helsinki, Finland (TL, MK), the Alma and K A Snellman Foundation, Oulu, Finland (TL), the Arvo and Lea Ylppö Foundation, Helsinki, Finland (TL), and the Foundation fo Paediatric Research in Finland (TL).

1 Greene SA, Frank M, Zachmann M, Prader A. Growth and sexual development in children with meningomyelocele. Eur F Pediatr 1985;144:146-8.

2 Rosenblum MF, Finegold DN, Charney EB. Assessment of stature of children with meningomyelocele, and usefulness of arm-span measurement. Dev Med Child Neurol 1983;25 338-42.

3 Kalen V, Harding C. Skeletal maturity in myelodysplasia. Dev Med Child Neurol 1994;36:528-32.

4 Kaiser G, Ruedeberg A, Arnold M. Endocrinological disorders in shunted hydrocephalus. $Z$ Kinderchir 1989;44 (suppl 1):16-7.

5 Löppönen T, Saukkonen A-L, Serlo W, Lanning P, Knip M. Slow prepubertal linear growth but early pubertal growth spurt in patients with shunted hydrocephalus. Pediatrics spurt in patients

6 Rotenstein D, Reigel DH. Growth hormone treatment of children with neural tube defects: results from 6 months to 6 years. F Pediatr 1996;128:184-9.

7 Rotenstein D, Breen TJ. Growth hormone treatment of children with myelomeningocele. F Pediatr 1996;128:S2831.

8 Hammock MK, Milhorat TH, August G, McKay D. Growth hormone (hGH) levels in patients with hydrocephalus. Z Kinderchir 1977;22:413-8.

9 Leveratto L, Picco P, Cama A, et al. Insulin-like growth factor I (IFG-I) in children with neural tube closure defects: preliminary report. Eur F Pediatr Surg 1993;3:19-20.

10 Amacher AL, Wellington J. Infantile hydrocephalus: longterm results of surgical therapy. Child's Brain 1984;11:21729

11 Serlo W. Shunt treatment of hydrocephalus in children [dissertation]. Acta Universitatis Ouluensis 1985; series D, medica 130 .

12 Saukkonen A-L. Childhood hydrocephalus. Electroencephalography, epilepsy and slit ventricle syndrome [disser-
tation]. Acta Universitatis Ouluensis 1989; series D, medica 185 .

13 Pääkkö E, Löppönen T, Saukkonen A-L, et al. Information value of magnetic resonance imaging in shunted hydrocephalus. Arch Dis Child 1994;70:530-5.

14 Sorva R, Perheentupa J, Tolppanen EM. New format for a growth chart. Acta Paediatr Scand 1984;73:527-9.

15 Dahlström S, Viikari J, Âkerblom HK, et al. Atherosclerosis precursors in Finnish children and adolescents. II. Height weight, body mass index, and skinfolds, and their correlations to metabolic variables. Acta Paediatr Scand 1985; suppl 318:65-78.

16 Owen GM. Measurement, recording and assessment of skinfold thickness in childhood and adolescence: report of a small meeting. Am f Clin Nutr 1982;35:629-38.

17 Parizkova J. Total body fat and skinfold thickness in children. Metabolism 1961;10:794-807.
18 Keys A, Brozek J. Body fat in adult man. Physiol Rev 1953; 33:245-51.

19 Mueller WH, Marbella A, Harrist RB, et al. Body circumferences as alternatives to skinfold measures of body fat distribution in children. Ann Hum Biol 1989;16:495506.

20 Tanner JM, Whitehouse RH. Clinical longitudinal standards for height, weight, height velocity, and stages of puberty. Arch Dis Child 1976;51:170-82.

21 Tapanainen P, Knip M. Evaluation of growth hormone secretion and treatment. Ann Med 1992;24:237-47.

22 Furlanetto R. Insulin-like growth factor measurements in evaluation of growth hormone secretion. Horm Res 1990;33:25-30.

23 Juul A, Bang P, Hertel N T, et al. Serum insulin-like growth factor-I in 1030 healthy children, adolescents and adults: relation to age, sex, stage of puberty, testicular size and relation to age, sex, stage of puberty, testicular size and
body mass index. $f$ Clin Endocrinol Metab 1994;78:744752 .

24 Rogol AD. Growth and growth hormone secretion at puberty: the role of gonadal steroid hormones. Acta Paediatr Suppl 1992;383:15-20.

25 Baxter RC, Martin JL. Structure of the MR 140,000 growth hormone-dependent insulin-like growth factor binding protein complex: determination by reconstitution and 902 .

26 Blum WF, Ranke MB, Kietzmann JK, Gauggel E, Zeisel HJ, Bierich JR. A specific radioimmunoassay for the growth hormone $(\mathrm{GH})$-dependent somatomedin-binding protein: its use for diagnosis of GH deficiency. F Clin Endocrinol Metab 1990;70:1504-12.

27 Blum WF, Albertson-Wikland K, Rosenberg S, Ranke MB. Serum levels of insulin-like growth factor I (IGF-I) and IGF binding protein 3 reflect spontaneous growth
hormone secretion. 7 Clin Endocrinol Metab 1993;76:16106.

28 Philips M, Chalew SA, Kowarski AA, Stene MA. Plasma IGFBP-3 and its relationship with quantitative growth hormone secretion in short children. Clin Endocrinol (Oxf) 1993;39:427-32.

29 Cohen P, Rosenfeld RG. Physiologic and clinical relevance of the insulin-like growth factor binding proteins. Curr Opin Pediatr 1994;6:462-7.

30 Löppönen T, Pääkkö E, Laitinen J, et al. Pituitary size and function in children and adolescents with shunted hydrocephalus. Clin Endocrinol (Oxf) 1997;47 (in press).

31 Albertsson-Wikland K, Rosberg S. Analyses of 24-hour growth hormone profiles in children: relation to growth. $\mathcal{F}$ Clin Endocrinol Metab 1988;67:493-500.

32 Löppönen T, Saukkonen A-L, Serlo W, Tapanainen P, Ruokonen A, Knip M. Accelerated pubertal development in patients with shunted hydrocephalus. Arch Dis Child 1996;75:490-6.

33 Sklar CA, Rothenberg S, Blumberg D, et al. Suppression of the pituitary-gonadal axis in children with central precocious puberty: effects on growth, growth hormone, insulinlike growth factor-I, and prolactin secretion. F Clin Endocrinol Metab 1991;73:734-8.

34 Williams T, Berelowitz M, Joffe SN, et al. Impaired growth hormone responses to growth hormone-releasing factor in obesity. N Engl F Med 1984;311:1403-7.

35 Kamp GA, Manasco PK, Barnes KM, et al. Low growth hormone levels are related to increased body mass index and do not reflect impaired growth in luteinizing hormonereleasing hormone agonist-treated children with precoreleasing hormone agonist-treated children with pre
cious puberty. $\mathcal{F}$ Clin Endocrinol Metab 1991;72:301-7.

36 Vanderschueren-Lodeweyckx $M$. The effect of simple obesity on growth and growth hormone. Horm Res 1993;40:2330

37 Loche S, Cappa M, Borelli P, et al. Reduced growth hormone response to growth hormone-releasing hormone in children with simple obesity: evidence for somatomedin-C mediated inhibition. Clin Endocrinol (Oxf) 1987;27:145-53.

38 Caufiez A, Golstein J, Lebrun P, et al. Relations between immunoreactive somatomedin C, insulin and T3 patterns during fasting in obese subjects. Clin Endocrinol (Oxf) 1984;20:65-70.

39 Minuto F, Barreca A, Del Monte P, et al. Spontaneous growth hormone and somatomedin-C/insulin-like growth factor-I secretion in obese subjects during puberty. F Endocrinol Invest 1988;11:489-95.

40 Wilson DM, Killen JD, Hammer LD, et al. Insulin-like growth factor-I as a reflection of body composition, nutrition, and puberty in sixth and seventh grade girls. 7 Clin Endocrinol Metab 1991;73:907-12.

41 Isojärvi JIT, Pakarinen AJ, Myllylä VV. A prospective study of serum sex hormones during carbamazepine therapy. Epilepsy Res 1991;9:139-44

42 Isojärvi JIT, Laatikainen T, Pakarinen A, Juntunen KTS, Myllylä VV. Polycystic ovaries and hyperandrogenism in women taking valproate for epilepsy. $N$ Engl $\mathcal{F}$ Med 1993;329:1383-8.

43 Isojärvi JIT, Laatikainen TJ, Knip M, Pakarinen AJ, Juntunen KTS, Myllylä V. Obesity and endocrine disorders in women taking valproate for epilepsy. Ann Neurol 1996;39:579-84. 